\title{
DETERMINASI WISATA THAILAND BERDASARKAN PERSEPSI WISATAWAN OUTBOND ASAL INDONESIA
}

\author{
Novita Delima Putri', Mima Nizma², Syahid ${ }^{3}$ \\ Universitas Indraprasta PGRI \\ TB. Simatupang, Jl. Nangka Raya No.58 C Jakarta Selatan \\ Email Korespondensi: syahid@unindra.ac.id
}

\begin{abstract}
ABSTRAK
Peneliti merumuskan beberapa masalah yang dihadapi terkait dengan Determinasi pasar wisata Thailand dengan berdasar pada aspek belanja dan kuliner yang telah memberikan pendapatan serta pertumbuhan ekonomi dari sektor pariwisata Thailand 1) bagaimana langkah determinasi pasar wisatawan yang telah dilakukan oleh pemerintah Thailand untuk menarik wisatawan asaing atau domestic, 2) bagaimana langkah membangun pengembangan pasar wisata di Indonesia berdasarkan aspek belanja dan kuliner. Hasil penelitian menunjukan bahwa makanan mennjadi salah satu motivasi wisatawan secara umum, makanan dan wisata merupakan duet yang cukup baik dalam meningkatkan jumlah wisatawan. Hal ini terjadi juga pada wisatawan inbound Indonesia ke Thailand. Terkait dengan wisata kuliner, berdasarkan hasil kuestioner, kesamaan kebiasaan, jenis makanan dan kesamaan budaya menjadi motivasi utama wisatawan Indonesia berkunjung ke Thailand.
\end{abstract}

Kata Kunci: Wisata kuliner, Wisatawan Indonesia, Thailand

\begin{abstract}
Researchers formulated several problems related to the determination of the Thai tourism market based on the shopping and culinary aspects that have provided funds and economic growth from the Thai tourism sector 1) How to determine the tourist market measures taken by Thailand to attract foreign or domestic tourists, 2) how to develop tourism development in Indonesia based on shopping and culinary aspects. The results showed that food is one of the motivations of general tourists, food and tourism is a pretty good duet in increasing the number of tourists. This also happened to tourists entering Indonesia to Thailand. Related to culinary tourism, based on the results of the questionnaire, challenging habits, types of food and challenging culture is the motivation of Indonesian tourists visiting Thailand.
\end{abstract}

Keywords: Culinary tourism, Buying Indonesia, Thailand 


\section{PENDAHULUAN}

Permintaan wisata semakin meningkat dari waktu kewaktu. Permintaan wisata meningkat seiring dengan kemajuan teknologi transportasi sehingga memudahnya mobilitas dari satu wilayah ke wilayah yang lain, kemajuan teknologi informasi yang memungkinkan terbukanya informasi tentang daerah tujuan wisata, semakin panjang waktu senggang yang tersedia dan dapat digunakan untuk berlibur (Yoeti, 2008), meningkatnya pendapatan masyarakat, kebijakan pemerintah dan aspek psikografis wisatawan (Murniati, 2008). Secara umum permintaan pariwisata juga akan meningkat seiring dengan semakin tingginya aktifitas masyarakat yang diiringi dengan semakin tingginya tingkat stress sehingga kegiatan rekreasi dan wisata semakin dibutuhkan. Bahkan WTO meyakini bahwa prospek pariwisata ke depan pun sangat menjanjikan bahkan sangat memberikan peluang besar, terutama apabila menyimak angka-angka perkiraan jumlah wisatawan internasional ( inbound tourism ) berdasarkan perkiraan WTO yakni 1,046 milyar orang (tahun 2010) dan 1,602 milyar orang (tahun 2020), diantaranya masing-masing 231 juta dan 438 juta orang berada di kawasan Asia Timur dan Pasifik. Dan akan mampu menciptakan pendapatan dunia sebesar USD 2 triliun pada tahun 2020.

Sektor pariwisata dapat menumbuhkan sektor - sektor lain dan ini merupakan salah satu dampak dari kegiatan wisata di suatu wilayah. Kegiatan wisata mampu menumbuhkan dan mengembangkan usaha pangan dan minuman yang bersifat lokal (Yoeti, 2008; 3), dimana dengan menciptakan keunikan dan keistimewaan sebuah produk wisata yang merupakan identitas dan ciri khas dari sebuah wilayah atau destinasi dapat menciptakan sebuah pembeda bagi wilayah atau destinasi lain. Dan diharapkankan strategi diffrensiasi dalam penciptaan produk wisata dapat memberikan sesuatu yang lebih bagi konsumen, dan lebih baik dari komputiter yang lain (Reilly, 2010).

Salah satu negara yang menggantungkan pendapatannya dari sektor wisata adalah Thailand, selain itu Wisata Thailand adalah salah satu destinasi wisata ungglan di Asia Tenggara yang memiliki tingkat produktifitas cukup tinggi. The Kingdom of Thailand ialah sebuah negara di Asia Tenggara yang berbatasan dengan Laos dan Kamboja ditimur, Malaysia dan Teluk Siam di selatan, dan Myanmar dan Laut Andaman di barat. Negara ini terdiri 76 provinsi (Changwat), yang dikelompokkan kedalam 5 kelompok Provinsi. Nama tiap provinsi berasal dari nama ibu kota provinsinya. Provinsi tersebut kemudian di bagi menjadi 795 distrik (Amphoe), 81 sub distrik(King Amphoe) dan 50 distrik Bangkok (khet) (Jumlah hingga tahun 2000) dan dibagi lagi menjadi 7.236 komunitas (tambon), 55.746 desa (Muban), 123 Kotamadya (Tesaban), dan 729 distrik sanitasi (Sukhaphiban) (jumlah hingga tahun 1984). Thailand juga memiliki pantai-pantai yang indah dan warisan budaya alam yang sangat memikat, serta obyek wisata belanja dan kuliner yang sangat beragam.

Pemerintah Thailand juga mengelola sektor industri pariwisata dalam memajukan perekonomian negara. Hal tersebut dibuktikan dengan meningkatnya jumlah wisatawan mancanegara yang datang ke Thailand setiap tahunnya yang sudah tentu membantu meningkatkan perekonomian negara. Industri pariwisata Thailand dikelola oleh dewan pariwisata Thailand yang disebut dengan Tourism Authority of Thailand (TAT). TAT merupakan badan pemerintah yang berada di bawah naungan departemen pariwisata dan olahraga (The Ministry of Tourism and Sports). Misi utamanya TAT adalah 
mempromosikan Thailand sebagai tujuan wisata bagi para pengunjung potensial di seluruh dunia, sekaligus mendukung pengembangan industri pariwisata Kerajaan.

Disisi lain perkembangan sektor wisata dan tingginya kebutuhan masyarakat dunia terhadap kegiatan wisata, membuat negara- negara lain berlomba- lomba untuk meningkatkan produktifitas wisatanya. Dengan demikian akan mengerucutkan Wisata Thailand pada pasar persaingan yang sangat ketat. Berdasarkan latar belakaang tersebut maka penting bagi peneliti untuk memetakan pasar wisata di Thailand. Diharapkan hasil penelitian dapat menjadi acuan dalam pengembangan pasar wisata di Indonesia, mengingat produktifitas sektor wisata di Thailand masih jauh didepan Indonesia, sehingga diharapkan Indonesia dapat menjadikan Thailand sebagai role model pengembangan wisata.

Dari latar belakang yang telah diuraikan, peneliti merumuskan beberapa masalah yang dihadapi terkait dengan Determinasi pasar wisata Thailand dengan berdasar pada aspek belanja dan kuliner yang telah memberikan pendapatan serta pertumbuhan ekonomi dari sektor pariwisata Thailand :

1. Bagaimana langkah determinasi pasar wisatawan yang telah dilakukan oleh pemerintah Thailand untuk menarik wisatawan asaing atau domestik?

2. Bagaimana langkah membangun pengembangan pasar wisata di Indonesia berdasarkan aspek belanja dan kuliner?

\section{METODE PENELITIAN}

Untuk melakukan sebuah penelitian kualitatif, perlu mengetahui tahap-tahap yang akan dilalui dalam proses penelitian. Tahapan ini disusun secara sistematis agar diperoleh data secara sistematis pula. Ada empat tahap yang bisa dikerjakan dalam suatu penelitian, yaitu :

a. Tahap Pra-lapangan Pada tahap pra-lapangan merupakan tahap penjajakan lapangan.

Ada enam langkah yang dilakukan oleh peneliti yaitu :

1) Menyusun rancangan penelitian

2) Pada tahap ini, peneliti membuat usulan penelitian atau proposal penelitian yang sebelumnya didiskusikan dengan para stakeholder

3) Memilih lapangan penelitian Peneliti memilih Tourism Authorithy of Thailand (TAT) karena merupakan lembaga/instansi yang di bentuk pemerintah Thailand untuk mengurusi segala hal tentang pariwisata yang ada di setiap daerah.

4) Menjajaki dan Menilai Lapangan Tahap ini dilakukan untuk memperoleh gambaran umum tentang keadaan Pariwisata yang ada Thailand. Agar peneliti lebih siap terjun ke lapangan serta untuk menilai keadaan, situasi, latar belakang dan konteksnya sehingga dapat ditemukan dengan apa yang dipikirkan oleh peneliti.

5) Memilih dan Memanfaatkan Informan Tahap ini peneliti memilih seorang informan yang merupakan orang yang benar-benar tahu dan terlibat dalam kegiatan di kantor TAT. Kemudian memanfaatkan informan tersebut untuk melancarkan penelitian.

6) Menyiapkan Perlengkapan Penelitian Pada tahap ini peneliti mempersiapkan segala sesuatu atau kebutuhan yang akan dipergunakan dalam penelitian ini. 
b. Tahap Lapangan Dalam tahap ini dibagi atas tiga bagian yaitu :

1) Memahami latar penelitian dan persiapan diri Tahap ini selain mempersiapkan diri, peneliti harus memahami latar penelitian agar dapat menentukan model pengumpulan datanya.

2) Memasuki Lapangan Pada saat sudah masuk ke lapangan peneliti menjalin hubungan yang akrab dengan subyek penelitian dengan menggunakan tutur bahasa yang baik, akrab serta bergaul dengan mereka dan tetap menjaga etika pergulan dan norma-norma yang berlaku di dalam lapangan penelitian tersebut.

3) Dalam tahap ini peneliti mencatat data yang diperolehnya ke dalam field notes, baik data yang diperoleh dari wawancara, pengamatan atau menyaksikan sendiri kejadian tersebut.

c. Tahap Analisa Data Analisa data merupakan suatu tahap mengorganisasikan dan mengurutkan data ke dalam pola, kategori dan satuan uraian dasar agar dapat memudahkan dalam menentukan tema dan dapat merumuskan hipotesa kerja yang sesuai dengan data. Pada tahap ini data yang diperoleh dari berbagai sumber, dikumpulkan, diklasifikasikan dan analisa dengan komparasi konstan.

d. Tahap Penulisan Laporan Penulisan laporan merupakan hasil akhir dari suatu penelitian, sehingga dalam tahap akhir ini peneliti mempunyai pengaruh terhadap hasil penulisan laporan. Penulisan laporan yang sesuai dengan prosedur penulisan yang baik karena menghasilkan kualitas yang baik pula terhadap hasil penelitian.

Thailand dipilih sebagai lokasi penelitian berdasarkan beberapa pertimbangan yaitu : 1) Thailand merupakan negara dengan marjet brief yang strategis, 2) Pasar Wisata thailand menyumbang tinggi bagi PDB Thailand, 3) Negara Thailand adalah negara berinfraskstruktur yang berkembang dengan baik, 4) Thailand memasuki ranking 16 dunia untuk natural and cultural resourcer. Desain penelitian yang digunakan dalam penelitian ini adalah determinasi dalam penetapan pasar wisatawan Thailand, dimana 1) untuk kemampuan manajemen /pengelola untuk melayani segmen pasar menjadi variabel sasaran, 2) mengetahui jenis, kuantitas, kualitas produk wisata, serta sumberdaya lainnya menjadi nilai variable mandiri tanpa membuat perbandingan atau hubungan atau pembuktian terhadap variable lain. penelitian ini adalah penelitian yang dilakukan peneliti dengan hanya menjelaskan data yang peneliti temukan dan dapati selama proses penelitian berlangsung. Dalam penelitian peubah yang diamati meliputi veriabel dependennya adalah wisatawan dan variabel independennya adalah determinasi penetapan pasar wisata.

\section{HASIL PENELITIAN DAN PEMBAHASAN}

Responden pada penelitian diklasifikasikan berdasarkan tiga aspek; aspek geografis (asal wisatawan), aspek demografis (usia, jenis kelamin), aspek psikologi (gaya wisata). Hasil rekapitulasi profile responden adalah sebagai berikut: 


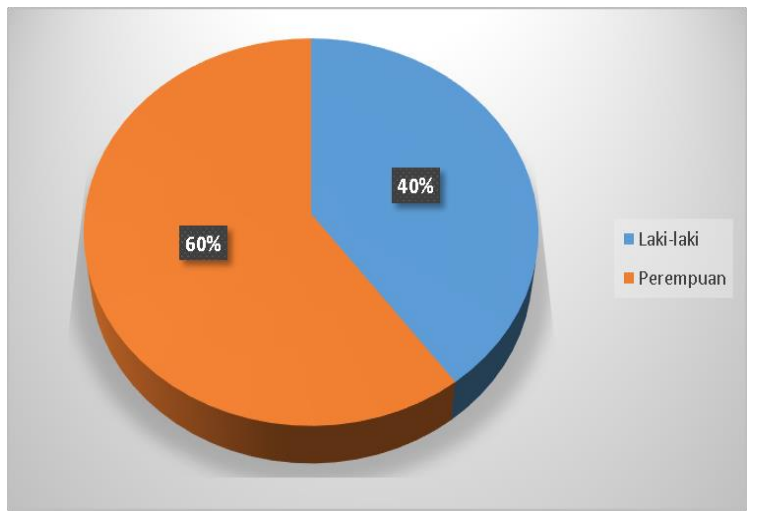

Gambar 1. Profil Jenis Kelamin Responden

Sumber: Data diolah, 2018

Berdasarkan gambar diatas, diketahui bahwa mayoritas reponden adalah Perempuan (18 orang) dibandingkan dengan responden laki-laki (12 orang). Aspek berikutnya adalah aspek demografis. Berikut adalah pemetaan usia responden,

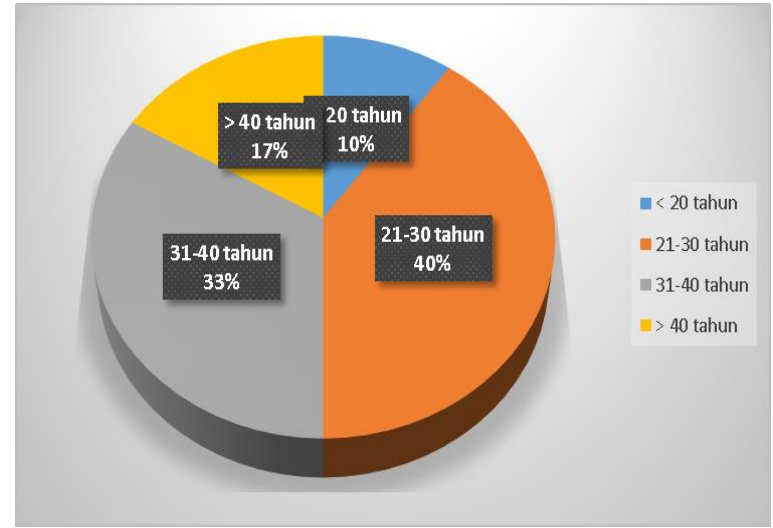

\section{Gambar 2. Profile Usia Responden}

Sumber : Data diolah, 2018

Gambar 2 menjelaskan bahwa mayoritas reponden berusia 21-30 tahun (40\%) dan usia 31-40 tahun (33\%), hal ini menunjukkan bahwa Thailand saat ini cukup popular bagi wisatawan usia remaja akhir dan dewasa. Masyoritas mereka berwisata dengan teman, kolega dan keluarga.

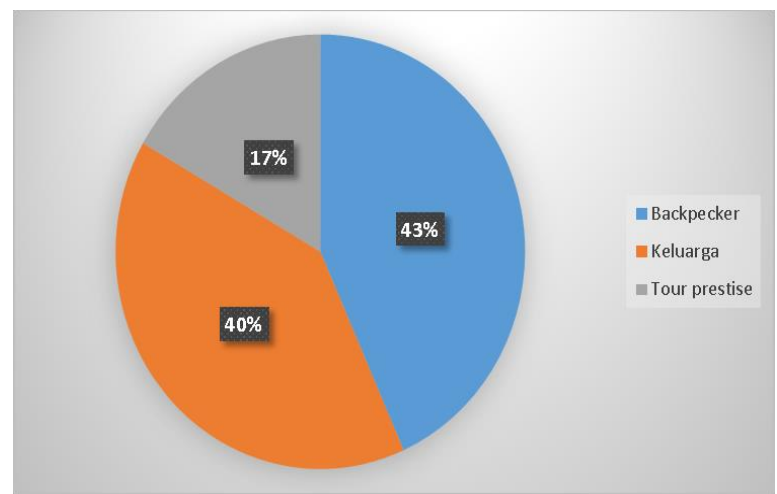

Gambar 3. Profile Gaya Wisata 
Berdasarkan data tersebut menjelaskan bahwa mayoritas wisatawan Outbound Indonesia ke Thailand adalah bergata backpercer (43\%) dan berkunjung dengan keluarga $(40 \%)$, hanya sedikit yang menggunakan gaya wisata perstise. Hal ini dikarenakan Thailand masih berada diwilayah ASEAN, Thailand juga terkenal dengan wisata yang cukup murah sehingga tidak terlalu membutuhkan biaya besar untuk berwisata ke Thailand.

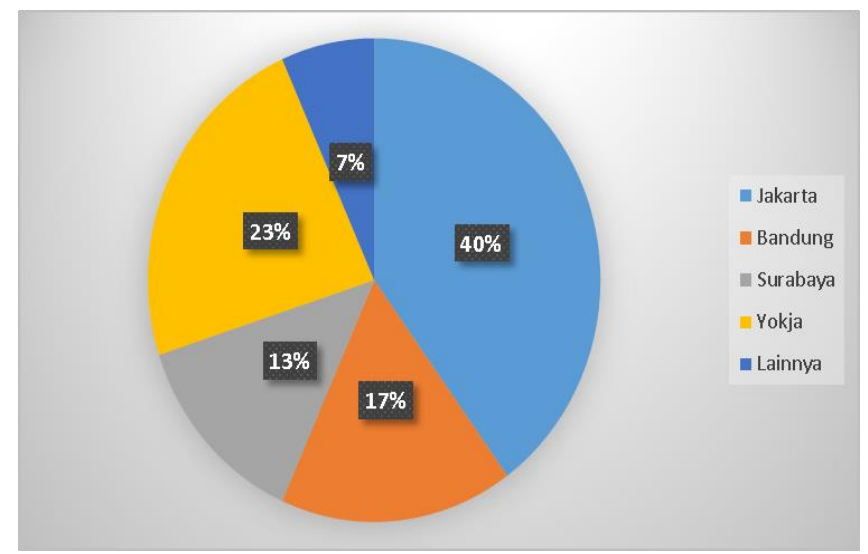

Gambar 4. Profile Gaya Wisata

Sumber : Data diolah, 2018

Berdasarkan data geografis atau wilayah asal wisatwan, mayoritas berasal dari Jakarta (40\%) dan berikutnya dari Jokja (23\%). Ketersediaan tiket promo menjadi salah satu yang menyebabkan masyarakat di satu wilayah berwisata di wilayah lainnya.

Terdapat 12 aspek motivasi wisata yaitu; Kesamaan Bahasa, kesamaan budaya, kesamaan nilai mata uang, kesamaan kebiasaan, kesamaan jenis makanan, kesamaan bahan makanan, kesamaan cara masak, kesamaan prosesi makan, kesamaan alat makan, kesamaan alat makan, kesamaan rasa makanan, aspek kehalalan makanan.

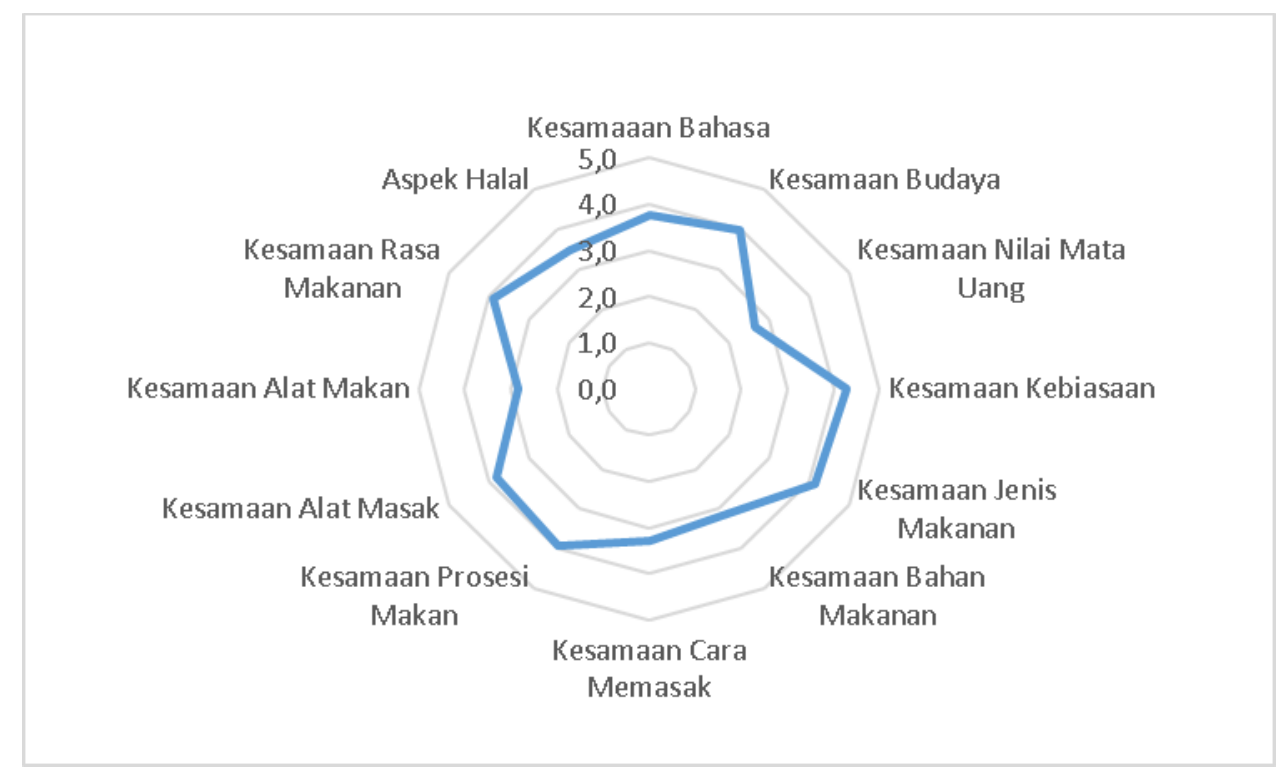

Gambar 5. Profile Gaya Wisata

Sumber : Data diolah, 2018 
Berdasarkan hasil penelitian menunjukan bahwa ke-duabelas aspek yang digunakan dalam penelitian memiliki score yang cukup tinggi/baik. Hal ini menunjukkan bahwa wisata khususnya wisata kuliner di Thailand cukup menenarik dan mempengaruhi motivasi wisatawan Indonesia untuk berkunjung ke sana.

Table 1. Rekapitulasi jawaban responden

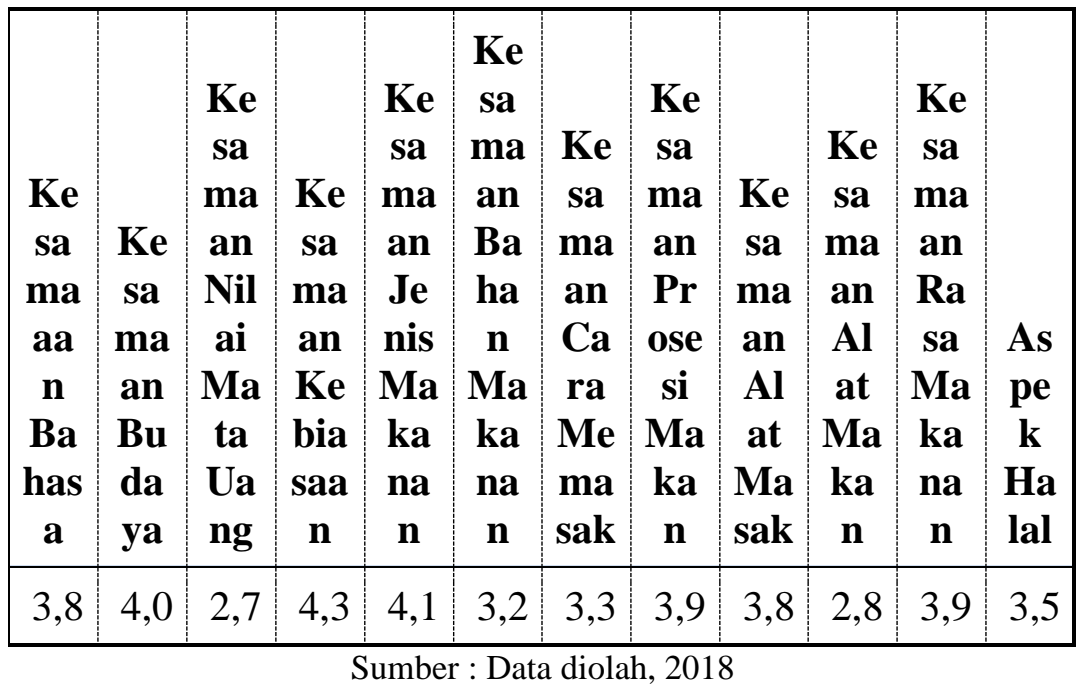

Hal yang sangat mempengaruhi motivasi wisatawab berkunjung ke Thailand adalah kesamaan Budaya, jika melihat secara geografis, wilayah Thailand Selatan berbatasan langsung dengan Malaysia dan budaya Melayu masih sangat kental. Selain itu wilayah Thailand Selatan dapat dicapai melalui jalur datar dari Penang, selain biaya yang murah, waktu yang rekatif secapat menjadi motovasi utama berkunjung ke Thailand.

Terkait dengan wisata kuliner, berdasarkan hasil kuestioner, kesamaan kebiasaan, jenis makanan dan kesamaan budaya menjadi motivasi utama wisatawan Indonesia berkunjung ke Thailand dengan nilai rata-rata berturut-turut $(4,3 ; 4,1$ dan 4,0).

\section{KESIMPULAN}

Makanan menenjadi salah satu motivasi wisatwan secara umum, makanan dan wisata merupakan duet yang cukup baik dalam meningkatkan jumlah wisatawan. Hal ini terjadi juga pada wisatwan inbound Indonesia ke Thailand. Terkait dengan wisata kuliner, berdasarkan hasil kuestioner, kesamaan kebiasaan, jenis makanan dan kesamaan budaya menjadi motivasi utama wisatawan Indonesia berkunjung ke Thailand. Dalam perkembangannya, wisata kuliner di Thailand dimana mayoritas beragama non muslim, seharusnya mulai membuat perencanaan yang cukup baik terkait wisatawan muslim, dimana wisatwan muslim memiliki pasar tersendiri yang cukup besar, sehingga aspek halal dan penggunaan alat masak, cara masak, bahan dan alat makan yang memenuhi kaidah syariah (halal) seharusnya mulai menjadi perhatoan bagi arah pengembangan wisata di Thailand. 


\section{TERIMA KASIH}

Apresiasi dan terima kasih kepada Direktorat Riset dan Pengabdian Masyarakat, Dirjen Penguatan Riset dan Pengembangan, Kementerian Riset, Teknologi dan Pendidikan Tinggi yang telah membiayai kegiatan Penelitian Dosen Pemula (PDP) Tahun 2018 dengan judul: "Determinasi pasar wisata Thailand (aspek belanja dan kuliner)". Terima kasih juga kepada LLDIKTI Wilayah III Jakarta dan Lembaga Penelitian dan Pengabdian Masyarakat Universitas Indraprasta PGRI yang telah membantu kegiatan penelitian ini melalui Kontrak Penelitian: 032/K3/PNT/2018, Tanggal 6 Maret 2018. Dan Surat Perjanjian/Kontrak Penelitian UNINDRA Nomor: /0311/SKP.LT/LPPM/UNINDRA/III/2018, Tanggal 12 Maret 2018.

\section{DAFTAR PUSTAKA}

Ariyanto, P. (2014). Strategi Singapure Tourism Board Dalam Meningkatkan Kunjungan Wisatawan Asal Indonesia Ke Singapure Pasca Krisis Global Tahun 2008. eJournal Ilmu Hubungan Internasional, 2 (1), 149-158.

Dewi, I. J. (2010). Implementasi dan Implikasi Kelembagaan Pemasaana Pariwisata yang Bertanggujawab (Responsible Tourism Marketing). Jakarta: Kementrian Kebudayaan dan Pariwisata Republik Indonesia.

Kotler, P., \& Keller, K. L. (2009). Manajemen pemasaran.

Murniati, D. (2008). Trend Pariwisata Korsel dan Peluang Indonesia. Trend Pariwisata Korsel Dan Peluang Indonesia, Jurnal Kepariwisataan Indonesia, 3. No.4.

Pitana, I. G., \& Surya Diarta, I. K. (2009). Pengembangan Ilmu Kepariwisataan Yokjakarta. Yogyakarta: Penerbit Andi.

Reilly, T. (2010). Vallue Added Selling; How to sell more prifitable, confidently and profesional by competing on value (3ed ed.). United State: Mc Graw Hill.

Wahab, W. (2002). Manajemen Kepariwisataan. Jakarta: Pradnya Paramita.

Warpani, S. (2007). Pariwisata Dalam Tataruang Wilayah. Bandung: ITB.

Yoeti, O. A. (2008). Ekonomi Pariwisata; Introduksi, Informasi dan Implementasi. Jakarta: Kompas Media Indonesia. 